\title{
AARP
}

S\&P Global

\section{Companies Expand Family-Friendly Policies, But Focus Favors Parents Over Caregivers}

Companies' pandemic policies are targeted more to parents than family caregivers December 17, 2020

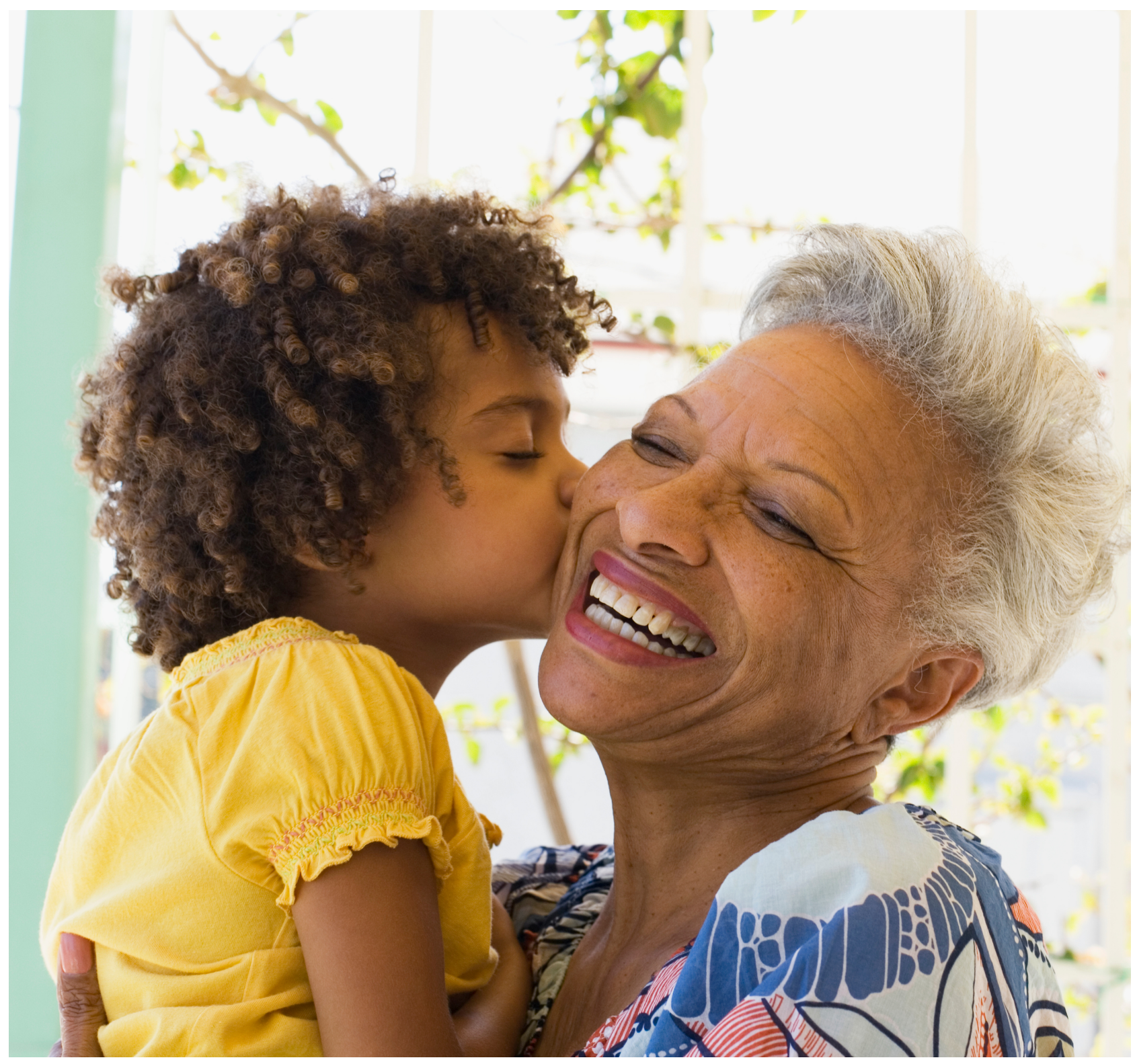




\title{
Companies Expand Family-Friendly Policies, But Focus Favors Parents Over Caregivers
}

\author{
Companies' pandemic policies are targeted more to parents than \\ family caregivers
}

Authors: Nathan Stovall, Azadeh Nematzadeh, and Laura Skufca

Contributors: Katie Darden, Lindsey White, Tricia Sandiego, Molly Mintz, and Victoria Schumacher

Executive Sponsors: Alexandra Dimitrijevic, S\&P Global, and Nancy LeaMond, AARP

\section{Introduction: Companies' pandemic policies are targeted more to parents than family caregivers}

The coronavirus crisis has increased the pressures and upended the boundaries between work and life at home for people working at U.S. companies - a blurring between the professional and personal that may prove especially challenging for those caring for young children, older adults, or family members and friends requiring additional care. Corporate America has recognized that many employees find their responsibilities at home have grown since the pandemic began, and companies have introduced many family-friendly policies to address those needs. Companies such as S\&P Global and AARP have provided employees with flexible work options, resource groups, back-up care, and even ad hoc days off to allow them to care for others or recharge.

A number of companies report that those changes have focused more on parents than family caregivers of adults with health or functional needs.

Some companies report having dedicated policies in place before the pandemic began, and say they continue to roll out creative offerings to meet employees' growing needs. Despite these pockets of progress, many employees with care responsibilities are dropping out of the workforce. As the U.S. population continues to age, and Baby Boomers reach older adulthood, the number of people needing care is only expected to rise. The U.S. Census Bureau projects that older adults, people age 65 and over, are projected to outnumber children for the first time ever beginning in 2034.

Because women still bear the bulk of family care responsibilities and continue to earn less than then men, many female employees could be forced to leave their careers to care for children or aging relatives and loved ones. 


\section{Methodology}

- S\&P Global and AARP examined Corporate America's family - leave policies to understand the relationship between family-friendly benefits and company performance.

- This research is based on an S\&P Global/AARP survey (fielded by Alan Newman Research) of 53 U.S. companies in the S\&P 1200 Index, which includes the 1,200 largest companies in the world. This survey was conducted from July 23-Oct. 1, and focused on U.S.-based companies, since there are federally mandated family-leave policies across much of the rest of the developed world. Due to the low sample size, these results should be interpreted with caution. While the sample in the survey may not represent the offerings of all companies in the S\&P 1200, the results offer a window into the innovation of benefits since the pandemic began.

- The research also draws from a previous survey S\&P Global and AARP conducted of 1,573 people ( $51 \%$ men and $49 \%$ women) who work for a firm with more than 1,000 employees, and was conducted from Aug. 20-Sept. 8.

- This research also uses S\&P Global Market Intelligence data showing the performance of companies and their respective sectors, and relies on interviews with executives from several large U.S. corporations.
S\&P Global, in partnership

with AARP, examined

Corporate America's

family-leave policies by

analyzing the relationship

between family-friendly

benefits, turnover, and

company performance-

since the U.S. private

sector has largely taken

the lead in such policies.

While some federal paid

leave mandates have been

introduced in the U.S. since

the pandemic began, these

mandates may not be long-

term and don't apply to the

largest companies in

America.

This research is

based on an S\&P

Global/AARP survey

of 53 U.S.

companies in the

S\&P 1200, which

includes the 1,200 largest companies in the world, to give an idea of the policies and benefits offered by large corporates before and after the pandemic began. Eighty-seven percent of companies responding to the survey had more than 1,000 employees. The technology, media and telecommunications sector made up the largest pool of companies responding to the survey, accounting for $21 \%$ of respondents. That was followed by financials, who represented $17 \%$ of respondents; the industrials sector, which accounted for 15\%; and the consumer sector, which totaled $11 \%$. Energy and utilities, healthcare, materials, and other sectors made up the remaining $36 \%$ of companies participating in the survey. This study follows an examination by S\&P Global and AARP of the relationship between family-friendly benefits and female representation in the workforce and senior management, which found that flexible benefits were essential to attract and retain talent in the current pandemic.

This latest study found that many institutions have responded to the pandemic by increasingly offering more flexible working arrangements for their employees. Companies also recognize that meeting employees' needs supports their bottom lines, and offering more family-friendly benefits tends to produce higher returns. However, this study also found that some companies aren't as familiar with the issue of family caregiving for adults, and instead favor supporting parents. As such, many firms don't have a formal written policy focused on employees providing care to aging relatives, family friends, or loved ones.

\section{The issue: Growing needs of parents, family caregivers push some out of the workforce}

Many parents and family caregivers have reported that their at-home commitments have grown since the pandemic began, leading to increased stress levels and some feeling that they were being penalized 
at work for their increasing responsibilities, according to an S\&P Global/AARP survey of nearly 1,600 people conducted in the late summer of 2020.

In the face of school and daycare closures, and with many children moving to virtual learning environments, the amount of time required for childcare duties since the pandemic began has increased for $58 \%$ of parents, according to the survey results.

Family caregivers have also seen their home commitments increase. Nearly $20 \%$ of the U.S. adult population provides care to an adult family member or friend, according to the National Alliance for Caregiving (NAC) and AARP's "Caregiving in the U.S. 2020" study. Half of family caregivers in the S\&P Global/AARP summer survey said their responsibilities have increased since the pandemic started.

In some cases, the demands at home have been great enough to push people out of the workforce. Even as unemployment has remained historically high due to the pandemic, many regions across the U.S. have continued to report tight labor markets, suggesting that there has been a shortage of qualified workers, particularly women, according to the Federal Reserve. In the December release of its Beige Book, which offers highlights on economic activity, employment, and wages eight times a year, the U.S. central bank attributed that shortage, seen across industries and including lower-skilled workers, to employees' health and childcare concerns and noted that many firms have consequently offered increased schedule flexibility.

\section{Companies try to respond with flexibility to employees' growing needs}

Many employees are seeking greater flexibility in their work schedules because that option could determine whether they can stay in the workforce or have to opt out to focus on caring for children, family members or other adult loved ones. Fifty-six percent of companies in the latest S\&P Global/AARP survey have implemented flexible work hours since the outbreak of COVID-19, and $48 \%$ of companies began offering mental-health or self-care resources within the same period.

\section{Practices Implemented Due To COVID-19}

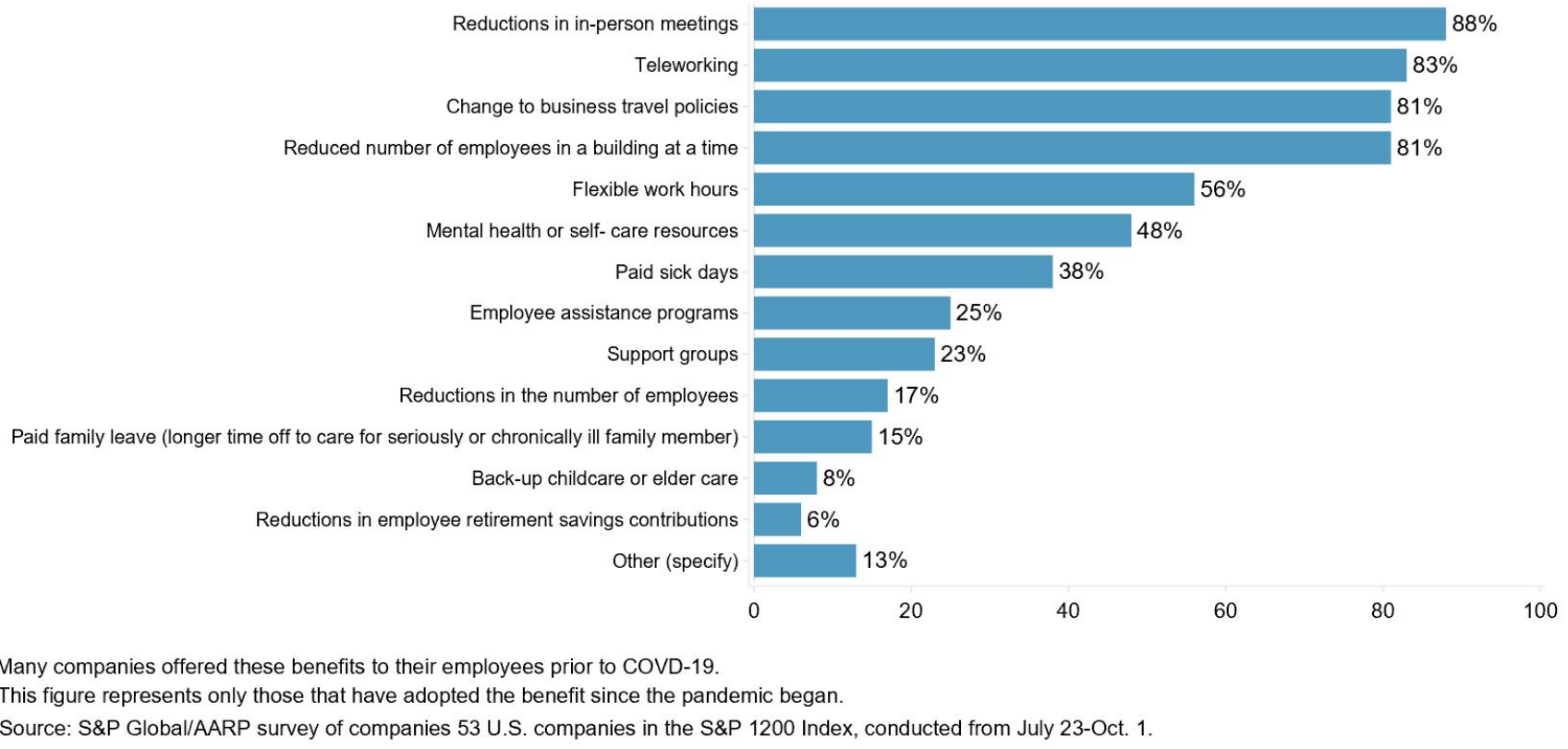


Most companies have taken some action to respond to employees' growing needs by adapting their policies and practices. More than $60 \%$ of respondents in the survey said they had increased the benefits and resources they offer since the pandemic began.

\section{Impact Of COVID-19 On Benefits/Resources}

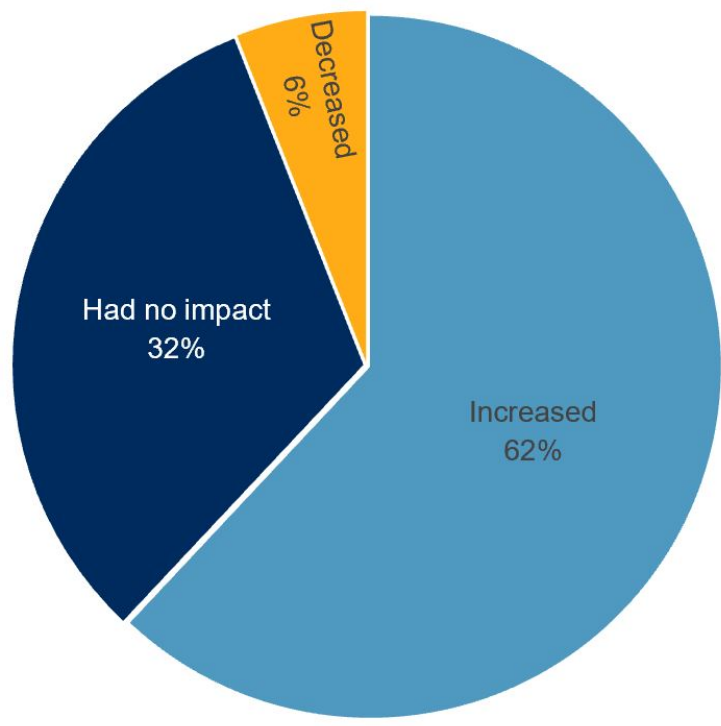

Source: S\&P Global/AARP survey of companies 53 U.S. companies in the S\&P 1200 Index fielded between July 23 and Oct. 1, 2020.

\section{Benefits more focused on parents caring for children than employees caring for adult family members with health or functional needs}

In some instances, the pandemic has elevated the corporate focus on offering benefits for family caregivers. Companies have historically created more robust paid parental leave policies for new parents than for those with family caregiving responsibilities.

Carol Sladek, a partner in the consumer experience practice at Aon Hewitt and founder and leader of the company's work-life consulting team, said in an interview in late summer that companies began to "dabble" with family-caregiving benefits prior to the coronavirus crisis, but the pandemic has made it an even bigger issue because companies don't want employees coming to work if they have an ill family member.

ViacomCBS was one such company that was in a solid position to respond to growing employee needs after the pandemic began, according to Michelle Martin, vice president of Total Rewards Experience at the company. She said in a November interview that the company already had backup daycare for children and adults in place. Ms. Martin further noted that ViacomCBS offers an elder care management program, where employees are assigned a dedicated coach to help them develop a caregiving plan for their situation, including offering at-home assessments to determine if modifications would improve caring for loved ones. 


\section{Companies Expand Family-Friendly Policies, But Focus Favors Parents Over Caregivers}

In addition, the company offers specific programs related to cancer, including one where an adviser through Memorial Sloan Kettering helps employees gather necessary medical records and walks them through the steps they need to take. The company recently launched a cancer-care pilot program that assists employees who are serving as caregivers with a wide variety of benefits, including navigating a cancer diagnosis or gaining financial support for a parent or older loved one.

Perhaps most notably, ViacomCBS began offering caregivers six weeks of paid leave in July. Ms. Martin said her company recognizes that the needs of parents and caregivers of adults are different.

"The one difference is that you can plan a little bit," Ms. Martin said of new parents versus caregivers. "The other is that it's an exciting and happy event in a lot of ways, right? You're adding to your family, you're building - whereas when you're caregiving, that could be potentially more challenging," both logistically and emotionally, she added.

While ViacomCBS has rolled out a number of benefits focused on caregivers and parents alike, many other companies have reported notable differences in the benefits they offer the two groups. Sixty-eight percent of the S\&P 1200 companies responding to the S\&P Global/AARP survey said they were very or somewhat knowledgeable about the needs of family caregivers of adults. Meanwhile, 94\% of respondents reported being knowledgeable of the needs of parents of young children.

That disparity exists despite the time commitment for at-home responsibilities between parents and family caregivers having been comparable since the pandemic started, as the S\&P Global/AARP survey of individuals conducted in late summer found. 


\section{Company Knowledge Of Caregiver/Parent Needs}

100

80

60

40

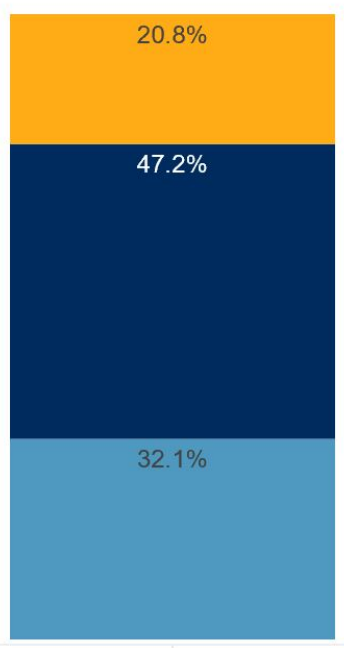

Family caregivers of adults

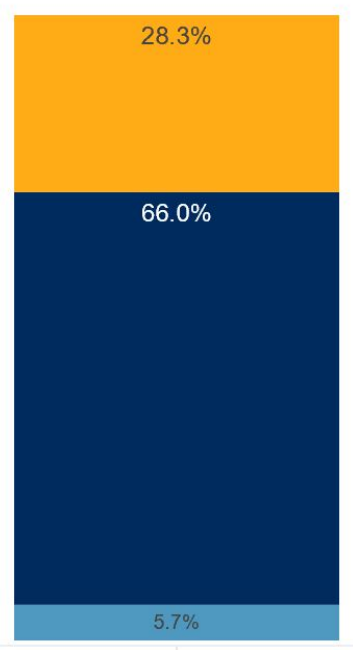

Parents of young children

Q9a/b. In general, what level of knowledge would you say your company has about the needs of

[family caregivers/parents of young children] in your workplace? (All respondents, $n=53$ )

Source: S\&P Global/AARP survey of companies 53 U.S. companies in the S\&P 1200 Index fielded between July 23 and Oct. 1, 2020.

That divide is evident in corporate culture, as well. While support for employees is high broadly, and companies say they are working to meet all of their employees' needs, respondents to the survey found that firms were generally more supportive of parents of young children than family caregivers of adults. Sixty-six percent of respondents said they were very supportive of parents with children age five or younger, while just 32\% of companies said they were very supportive of family caregivers. Similarly, 60\% of respondents said benefits for parents are a high priority or one of the top priorities at their company-compared to only $30 \%$ for family caregivers of adults.

\section{Supportiveness Of Company Culture}

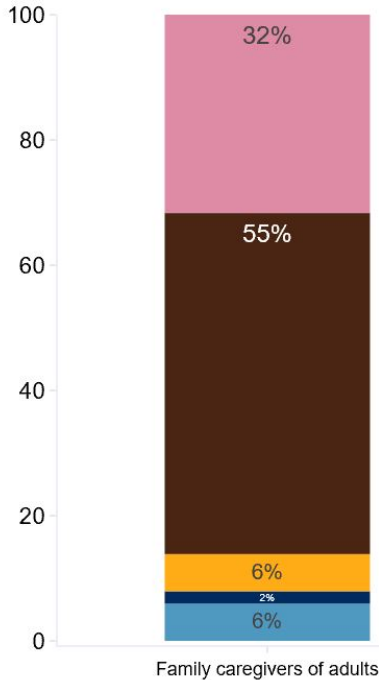

Family caregivers of adults

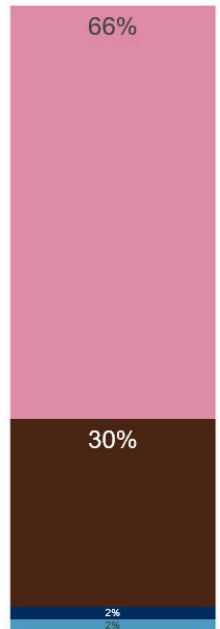

Parents of children age five or younger

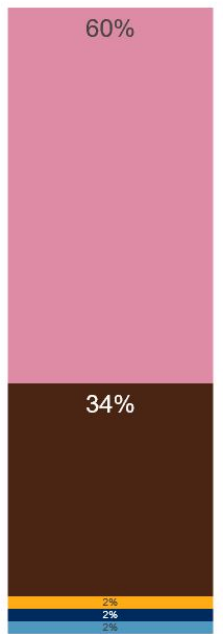

Parents of all minor children
Very knowledgeable

Somewhat knowledgeable

Not knowledgeable 
There are a variety of factors that could explain the shortfall, one prominently being that many companies don't have a codified inclusive policy around family caregiving. Many respondents to the survey indicated they were supportive of family caregivers in the workplace, but nearly $80 \%$ didn't have a formal, written policy pertaining to family caregivers of adults, and prefer to handle it on a case-by-case basis. Only $53 \%$ of caregivers said their employer is aware of their caregiving role, according to the NAC/AARP "Caregiving in the U.S. 2020" study.

\section{Policies Regarding Family Caregivers Of Adults}

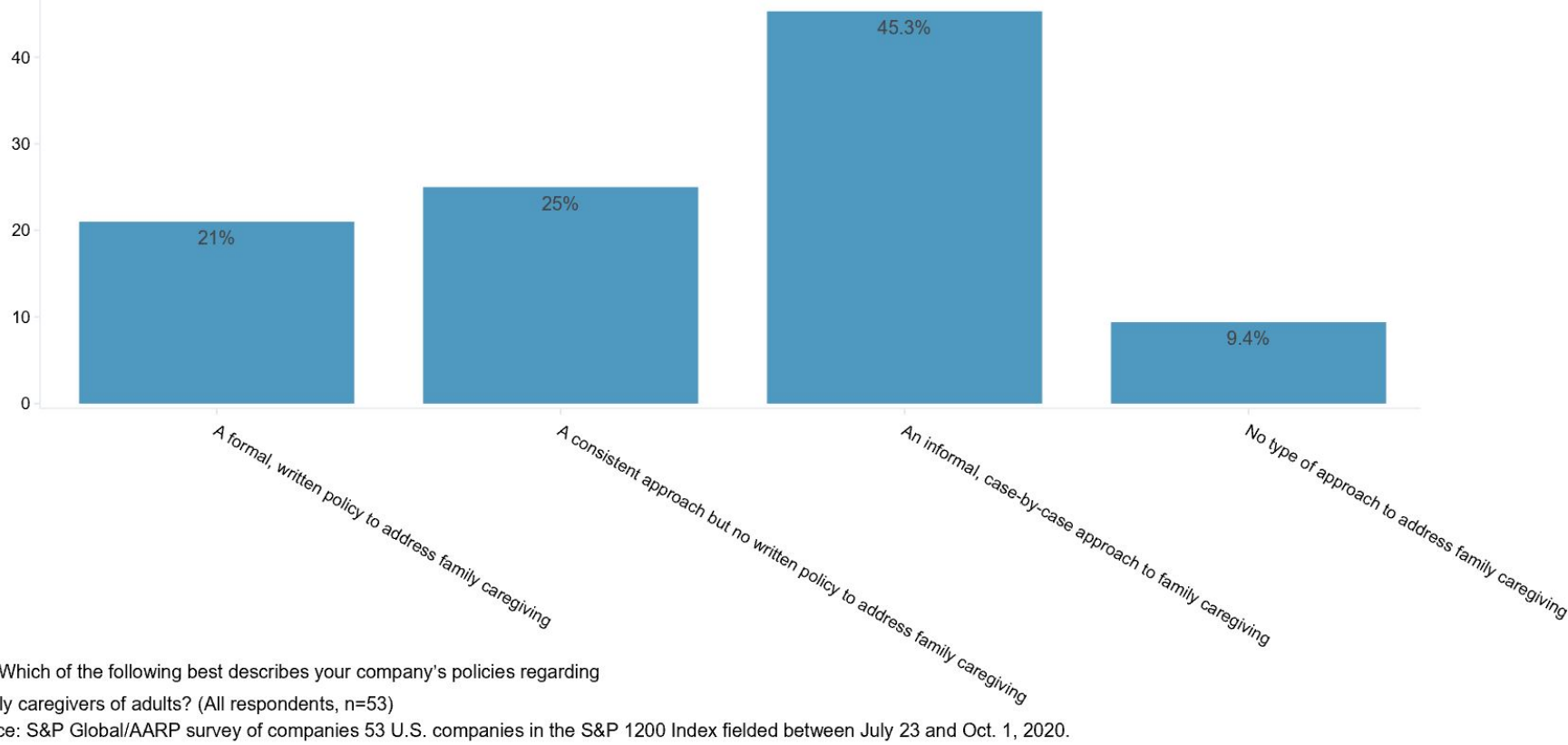

\section{Benefits implemented during pandemic could outlast the crisis}

There is some hope that the benefits offered to family caregivers and parents alike could permanently change because of the pandemic. Respondents to the survey of S\&P 1200 companies, people participating in the S\&P Global/AARP survey conducted in the summer, and executives interviewed for this research consistently said that more companies are now offering enhanced family-friendly policies and benefits. However, there is some concern that the expansion could only be temporary and that companies could revert to their previous approach once the pandemic ends.

ViacomCBS' Ms. Martin said the six weeks of paid family leave her company recently implemented would remain in place after the pandemic ends. When evaluating benefits, Ms. Martin said the company looks at other offerings in the marketplace to serve as benchmarks, but also considers the ability to attract and retain talent when initiating any policy. She also said that sharing personal stories on how employees have utilized benefits can help sell an initiative to a management team.

"When your leadership hears those, it becomes just very real to them," Ms. Martin said. "You're not signing a contract that you're going to be here for 10 years, but employees saying that they would certainly like to be is almost as good." 
Respondents to the S\&P Global/AARP survey of S\&P 1200 companies did indicate that some of their new benefits are likely to become permanent policies. For instance, $96 \%$ of companies that have rolled out mental-health or self-care resources since the coronavirus crisis started plan to make that offering permanent. However, the companies didn't provide such strong assurance for many of the caregiving benefits enacted due to COVID-19. Only $50 \%$ of companies plan to continue offering backup childcare or elder care and just $44 \%$ plan to offer paid sick days.

Fifty-nine percent of companies responding to the survey said they will make flexible work hours a permanent change, while just 38\% plan to continue offer teleworking. Such flexibility has played a key role in keeping a number of women in the workforce, since they still bear the bulk of family-care responsibilities, and a sizable gender pay gap across industries persists.

\section{Permanence Of Practices Implemented Due To COVID-19}

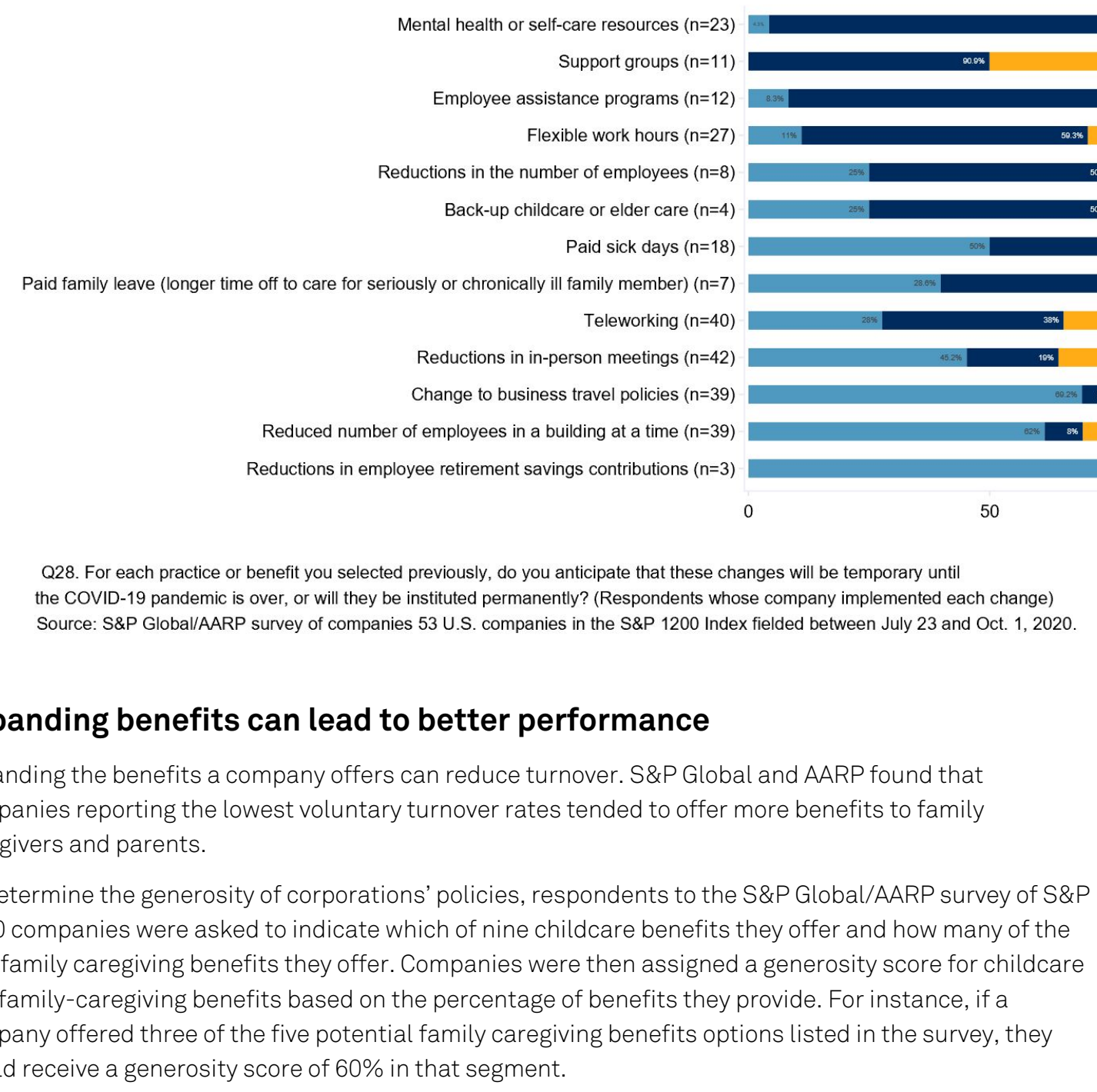


Companies that reported a voluntary turnover in the range of 1\%-6\% annually had a median familycaregiving generosity score of $50 \%$, compared to $33.3 \%$ among companies with turnover rates of $6 \%$ $11 \% ; 50 \%$ among companies with turnover rates of $11 \%-16 \%$ and $50 \%$ among companies with turnover greater than $16 \%$.

The box chart below separates companies that participated in the S\&P 1200 survey by voluntary turnover rate into four different groups, and subsequently shows the dispersion of generosity of family-care policies in each group. In each group, the median score is represented by the line in each box. Companies ranking in the first quartile appear below the line, while companies ranking in the third quartile appear above the line. The highest generosity score appears at the top of the line for each group, while the lowest score appears at the bottom of each line.

\section{Family Care Policies And Turnover}

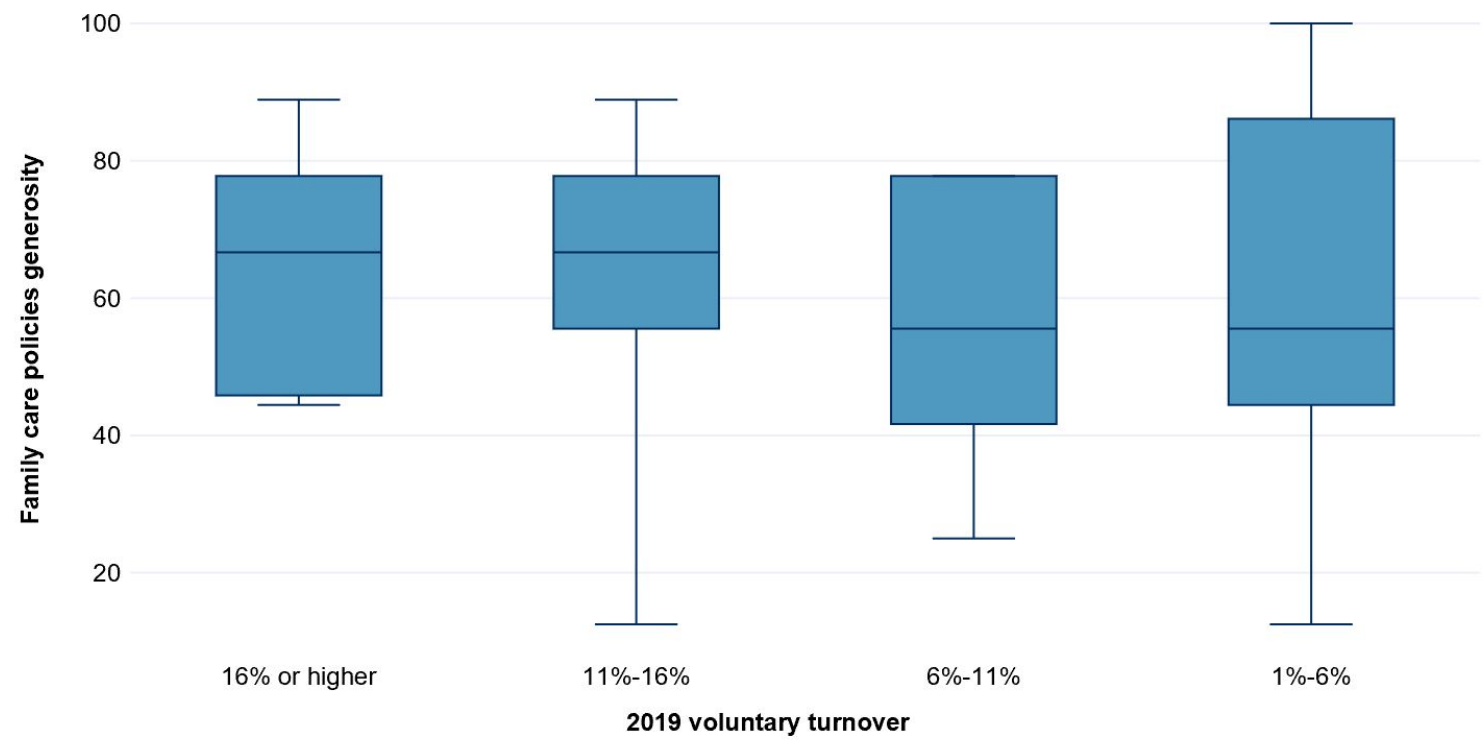

Source: S\&P Global/AARP survey of companies 53 U.S. companies in the S\&P 1200 Index fielded between July 23 and Oct. 1, 2020 .

The divide is more noteworthy when examining childcare policies. Companies with higher turnover rates seem to offer more generous childcare policies, perhaps as a carrot to mitigate elevated turnover. Companies that reported a voluntary turnover rate of 1\%-6\% had a median childcare generosity score of $55.6 \%$. In comparison, the median generosity score was also $55.6 \%$ among companies with turnover rates of $6 \%-11 \%$, but $66.7 \%$ among companies with turnover rates $11 \%$ or higher.

The box chart below separates companies that participated in the S\&P 1200 survey by voluntary turnover rate into four different groups, and subsequently shows the dispersion of generosity of childcare policies in each group. In each group, the median score is represented by the line in each box. Companies ranking in the first quartile appear below the line, while companies ranking in the third quartile appear above the line. The highest generosity score appears at the top of the line for each group, while the lowest score appears at the bottom of each line. 


\section{Childcare Policies And Turnover}

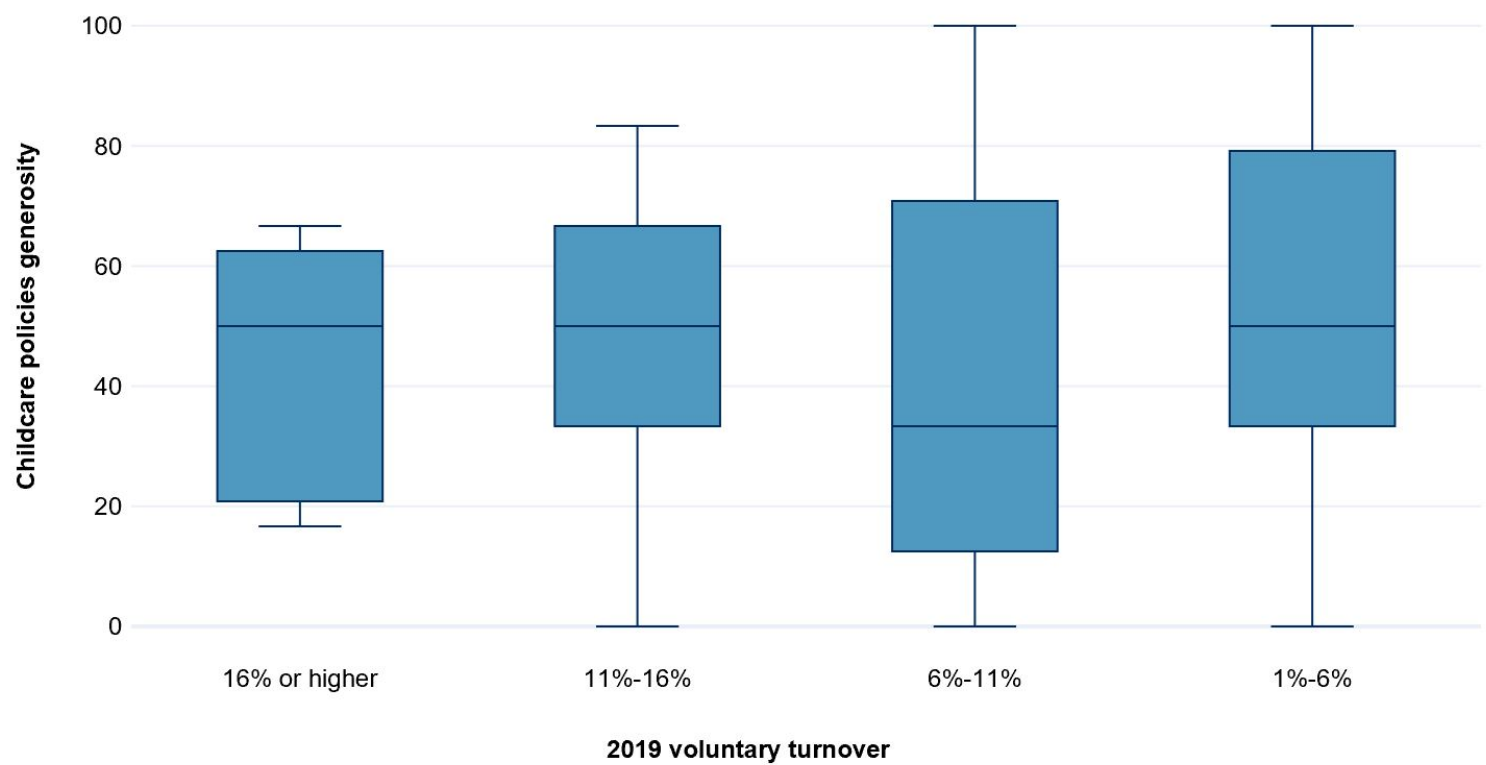

Source: S\&P Global/AARP survey of companies 53 U.S. companies in the S\&P 1200 Index fielded between July 23 and Oct. 1, 2020.

Additionally, companies in the survey with more generous family-friendly policies had produced stronger returns. S\&P Global and AARP examined the return on average equity for the 53 companies that participated in the survey, and subsequently compared those figures against their respective sectors' average returns. A statistically significant correlation between companies with above-average returns in their respective sectors and the generosity of their childcare and family caregiving policies is evident.

\section{Generosity Of Policies And Returns}

$\begin{array}{rrr}\begin{array}{r}\text { Generosity of } \\ \text { childcare policies }\end{array} & \begin{array}{r}\text { Generosity of family } \\ \text { caregiving policies }\end{array} & \begin{array}{r}\text { Generosity of } \\ \text { other benefits }\end{array}\end{array}$

Return on

average equity

0.408365

0.365323

0.285182

2019

\section{Return on}

average equity

last-twelve-

0.317397

0.310718

0.238485

months

Sources: S\&P Global Market Intelligence; S\&P Global/AARP survey of companies 53 U.S. companies in the S\&P 1200 Index fielded between July 23 and Oct. 1, 2020. 
Companies seem to recognize that more generous policies contribute to their bottom lines. Two-thirds of respondents believe that supporting family caregivers supports the bottom line, while $74 \%$ of respondents believe that supporting parents of children age five or younger leads to stronger financial results.

Very few S\&P 1200 companies surveyed said they think supporting family caregivers or parents has a negative effect on results. Fewer than 5\% indicated that they believe those benefits hurt their bottom lines.

\section{Perceived Impact Of Support On The Company's Bottom Line}

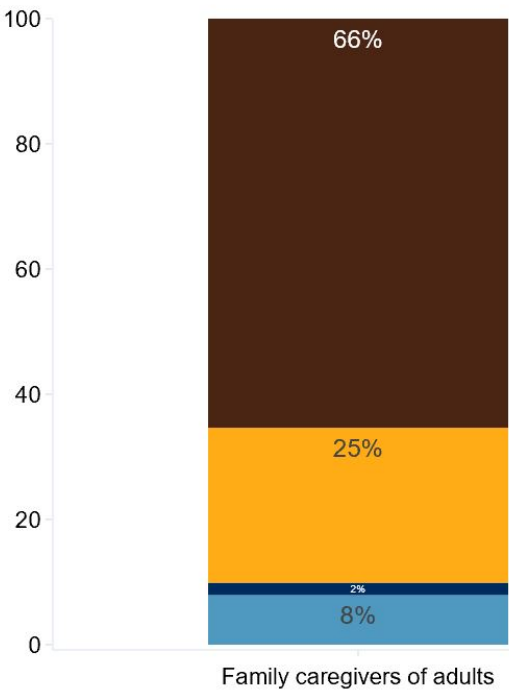
affects your company's bottom line? (All respondents, $n=53$ )

Source: S\&P Global/AARP survey of companies 53 U.S. companies in the S\&P 1200 Index fielded between July 23 and Oct. 1, 2020.

The S\&P 1200 companies surveyed agreed that supporting parents and caregivers yields a wide variety of positive effects. Still, a greater number of respondents saw the benefits of offering support for parents than for caregivers, further demonstrating the divide between the two groups and the potential need for greater education on the issue of family caregiving.

For instance, $89 \%$ of respondents strongly agreed that supporting parents strengthened morale, compared to $69 \%$ that said doing so for family caregivers had the same result. Nearly $80 \%$ of respondents strongly agreed that supporting parents helps attract talent, compared to the $35 \%$ that said the same about supporting caregivers. 


\section{Agreement With Statements Regarding Supporting Family Caregivers/Parents Of Young Children In The Workplace}

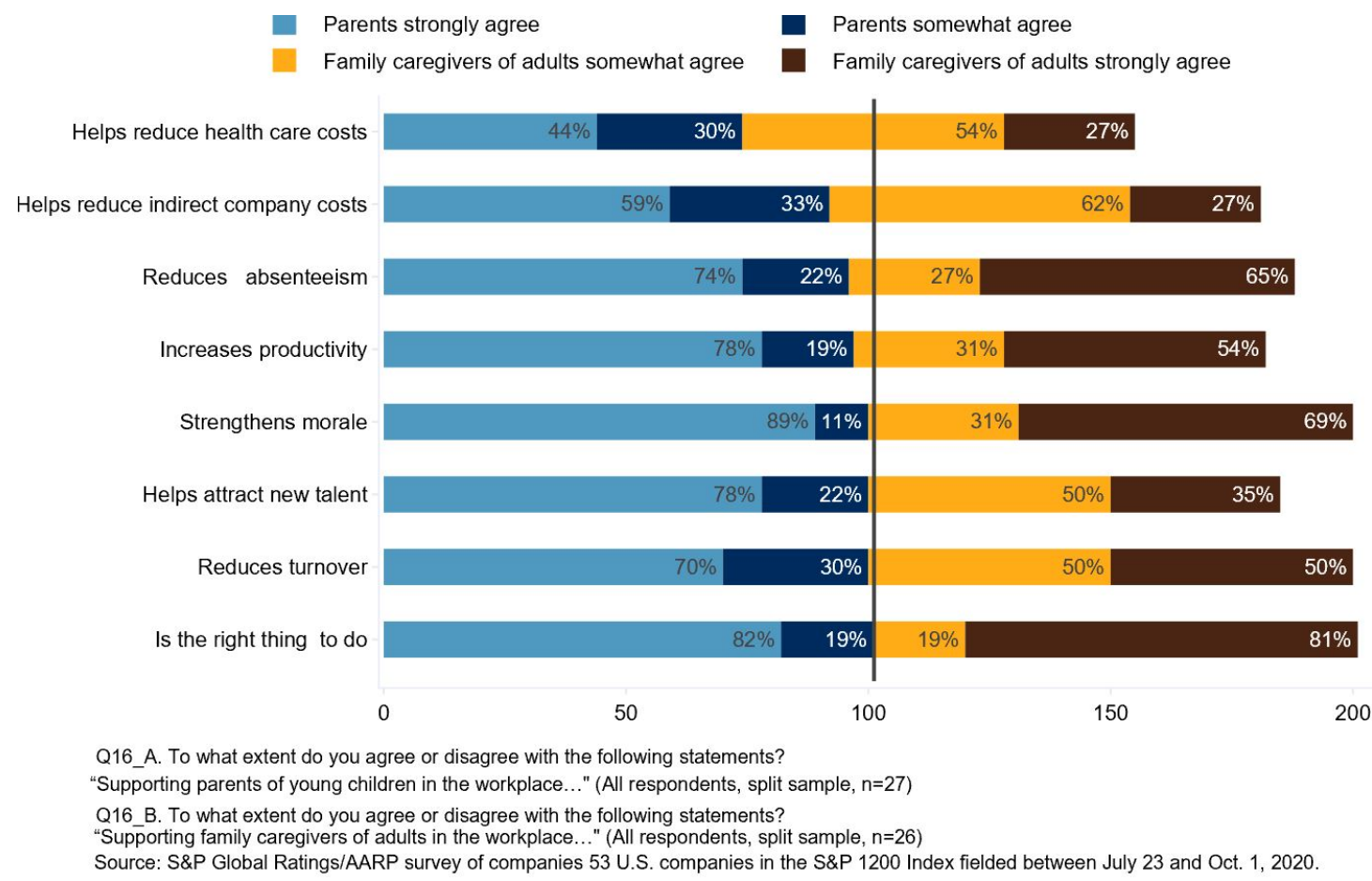

\section{Conclusion: Benefits have expanded but caregivers aren't getting as much attention}

As many corporations have responded to the growing needs of employees by expanding the benefits they offer, including much-needed flexibility in workdays and workplaces, the expansion has been uneven between parents and family caregivers.

Failing to narrow that gap could push some employees out of the workforce as the number of people needing care is expected to rise as Baby Boomers age. One potentially positive outcome of the pandemic is that some enhanced benefits for both parents and caregivers could be here to stay.

Companies that have rolled out more generous policies have lower turnover rates and higher returns than their peers with less-supportive offerings. That outperformance might even allow those companies to compete more effectively and encourage companies with less family-friendly offerings to reconsider their benefit policies. 